\title{
THE NOVEMBER MEETING IN PASADENA
}

The six hundred sixth meeting of the American Mathematical Society was held at the California Institute of Technology in Pasadena, California on Thursday, Friday, and Saturday, November 2123,1963 . There were 246 registrants at this meeting, 223 of whom were members of the Society.

By invitation of the Committee to Select Hour Speakers for Far Western Sectional Meetings, and with the financial support of the National Science Foundation, a Symposium on Recent Developments in the Theory of Numbers was held on Thursday and Friday. The program committee for this symposium consisted of Professors Leonard Carlitz, D. H. Lehmer, W. J. LeVeque, and A. L. Whiteman, Chairman. The members or the organizing committee served as chairmen of the four sessions of the Symposium. There were four principal addresses at the Symposium. Professor Atle Selberg of the Institute for Advanced Study lectured on The estimation of Fourier coefficients of modular forms and Kloostermann sums and their generalizations. He was introduced by Professor Harvey Cohn. Professor Kenkichi Iwasawa of the Massachusetts Institute of Technology spoke on Some results on cyclotomic fields. Professor Olga Taussky Todd introduced Professor Iwasawa. Conjectures on elliptic curves was the title of an address by Professor Bryan J. Birch of The University, Manchester, England. Professor Birch was introduced by Profesor D. J. Lewis. The last principal address was given by Professor Leonard Carlitz of Duke University. The title of his talk was Generating functions. Professor Carlitz was introduced by Professor Gordon Pall. The following twenty invited fifteen minute addresses were presented at the sessions of the Symposium: p-adic forms, Professor D. J. Lewis, University of Michigan; Uniform distribution, Professor W. J. LeVeque, University of Michigan and University of Colorado; Characters and cyclotomy, Professor Marshall Hall, Jr., California Institute of Technology; Theorems on Brewer and Jacobsthal sums, Professor A. L. Whiteman, University of Southern California; On the lack of unique factorization in quadratic fields, Professor Ivan Niven, University of Oregon, and Professor Herbert S. Zuckerman, University of Washington; On the degrees of polynomials irreducible over a field, Professor E. G. Straus and Professor B. Gordon, University of California, Los Angeles; Bounds for class numbers, Professor Morris Newman, National Bureau of Standards; Some new results connected with matrices of rational integers, Dr. E. C. Dade and Professor Olga Taussky Todd, California Institute of Technol- 
ogy; Block designs and quadratic forms, Dr. E. T. Parker, Sperry Rand Corporation; On the reight of a genus of positive n-ary quadratic forms, Professor Gordon Pall, Louisiana State University; The sieve method, Professor N. C. Ankey, Massachusetts Institute of Technology; Primes represented by irreducible polynomials in one variable, Professor Paul T. Bateman, University of Illinois; Sets of values taken by Dirichlet's L-series, Professor Tom M. Apostol, California Institute of Technology; On the divisor problem, Professor S. Chowla, University of Colorado, and Professor H. Walum, Harvey Mudd College; On p-adic analysis, Professor Bernard M. Dwork, Johns Hopkins University; Bounded consecutive residues and related problems, Professor W. H. Mills, Yale University; Second moments in additive number theory, Professor Leo Moser, University of Alberta; Extremal problems in number theory, Professor Paul Erdös, University of Alberta, Canada; On the shape of the fundamental domain for certain Hilbert modular functions, Professor Harvey Cohn, University of Arizona; Representations of discrete groups, Professor Joseph Lehner, University of Maryland. During the second session of the Symposium, Professor D. H. Lehmer gave a brief talk on the work of the late Morgan Ward in number theory. The Proceedings of the Symposium on Recent Developments in Number Theory will be published by the Society.

By invitation of the Committee to Select Hour Speakers for Far Western Sectional Meetings, Professor Kai Lai Chung of Stanford University addressed the Society on Saturday. His talk was entitled Boundary theory for Markov chains. Professor Chung was introduced by Professor H. F. Bohnenblust.

There were four sessions for contributed papers on Saturday with Dr. John Brillhart, Professor D. G. Cantor, Dr. E. C. Dade, and Professor E. H. Ostrow presiding.

Seattle, Washington

R. S. PiERCE, Associate Secretary 